\title{
An Observational Study on drug Utilization Pattern and Pharmacovigilance of Antidepressant Drugs
}

\author{
Authors \\ Dr A. Hussain ${ }^{1 *}$, Prof Dr M.Sekkizhar ${ }^{2}$, Dr M. Asok Kumar ${ }^{3}$, Dr P.Niramala ${ }^{4}$ \\ ${ }^{*}$ Final Year Post Graduate, Department of Pharmacology, Rajah Muthiah Medical College, Annamalai \\ University, Chidambaram \\ ${ }^{2}$ Professor, Department of Pharmacology, Rajah Muthiah Medical College, Annamalai University, \\ Chidambaram \\ ${ }^{3}$ Professor, Department of Psychiatry, Rajah Muthiah Medical College, Annamalai University, \\ Chidambaram \\ ${ }^{4}$ Professor and Head, Department of Pharmacology, Rajah Muthiah Medical College, Annamalai University, \\ Chidambaram \\ *Corresponding Author \\ Dr A. Hussain
}

Email: imthiyashussain37@gmail.com

\begin{abstract}
Introduction: Drug utilization is the marketing, distribution, prescription and the use of drugs in a society. The method of prescribing antidepressant drugs have changed worldwide in the last couple of years. ${ }^{1}$ Numerous drugs are seen in this class with different mechanism of action and variable efficacy and safety profile. $^{2}$ Drug utilization studies are important for rational prescribing, as there is discovery of new drugs and the delayed recognition of their adverse effects. Depression requires chronic treatment thus making such studies important in minimizing the medication errors. ${ }^{3}$

Methods: After getting approval from the instituitional human ethics committee and consent from the subjects, this study was conducted in which 80 prescriptions with one or more antidepressant drug was collected during a period of one year. The patients were followed up after one month and adverse events if any produced by medication were noted and analysed.

Results: Out of 80 prescriptions analysed, $46.25 \%$ were males and $53.75 \%$ were females. Regarding the morbidity distribution, depressive disorder contributes to $68.75 \%$ and adjustment disorder contributes to $8.75 \%$ of diagnosis. Based on analysis by WHO/INRUD standard guidelines, the average number of drugs and antidepressant drugs per prescription were $2.7 \%$ and $1.01 \%$ respectively. The utilization of antidepressant drugs assessed by PDD/DDD ratio is equal to 1 for sertraline and escitalopram while it is less than one for other antidepressants. The adverse effects commonly encountered were weight gain, sedation, dry mouth, diarrhea, insomnia and constipation.

Keywords: Depressive disorder, Adjustment disorder, Other anxiety disorder, Schizoaffective disorder, Obsessive compulsive disorder, Alcohol dependence, International network for rational use of drugs (INRUD).
\end{abstract}




\section{Introduction}

Major depressive disorder (MDD) is one of the leading cause of disability in the developed world. In addition, major depression is associated with a variety of medical conditions from chronic pain to coronary artery disease. 1 Depressive episodes are characterized by sad mood, pessimistic worry, decreased interest in routine activities, poor concentration, insomnia or increased sleep, weight loss or weight gain because of changed eating patterns, feeling of guilt, decreased libido. 2 Antidepressants (AD are used in the management of depressive disorders and anxiety disorders. Additionally, antidepressants are used in the treatment of eating disorders, impulse control disorders, enuresis, sexual dysfunction, aggression. ${ }^{4}$

Drug utilization study has been defined by the World Health Organization (WHO) as "marketing, distribution, prescription and use of drugs in a society with special emphasis on the resulting medical, social, economic consequences." The principal objective of drug utilization research is to enable rational use of drugs which is hard to find without the knowledge of prescription pattern. The analysis of prescribing patterns is to evaluate and suggest modifications if required in the prescribing pattern of medical practitioners to make medical practise rational and cost-effective. Prescribed daily dose (PDD) is the average daily dose prescribed which is prescribed according to a representative sample of population and is an indicator of the actual quantity of the drug or class of drug used per day over a given time period per user. ${ }^{5}$ Changes in prescription pattern over a time are expected and what influences this change is a valuable tool in our understanding of drug use. Hence our research applies drug utilization studies to describe the prescription pattern of antidepressant drugs.

This study was conducted to analyse the drug utilization pattern of antidepressants with the following objectives-

1. To analyse the drug utilization pattern by using standard parameters.
2. To delineate the various drugs used in depressive disorder.

3. Documenting adverse drug reactions reported or experienced by the patient.

Since drug utilization data of antidepressants are scarce, we conducted a study to describe the observed pattern of antidepressants use.

\section{Materials and Methods \\ Methodology}

Study design: A prospective observational study was conducted to analyse the drug utilization pattern of the various antidepressant drug prescribed and adverse effects with respect to antidepressant drugs.

Study area: This study was conducted in psychiatric OPD of Rajah Muthiah Medical College and hospital, a tertiary care teaching hospital under Annamalai University, Chidambaram, Tamilnadu, India.

Study period: The study was conducted during the period of July 2017 to June 2018.

Sample size: Eighty prescriptions were analysed on the basis of standard guidelines.

Inclusion criteria: Patients attending psychiatric OPD, RMMCH irrespective of age and sex with prescription having at least one antidepressant drug.

\section{Exclusion criteria}

1. Patients who are not willing to participate in the study.

2. Patients who could not comply with the study such as severe mental retardation and unconsciousness.

Study procedure: The proposal for this drug utilization study has been submitted to The Institutional Human Ethics Committee, Rajah Muthiah Medical College, Annamalai university and the approval was obtained before the commencement of the study. The data of the patients visiting psychiatric OPD during the period July 2017 - June 2018 were collected.

The individual participant was explained about the study and they were also assured that their identity would be kept confidential and they have the option to refuse participation in the study. 
Informed consent was obtained from the $\mathrm{s}$ participant prior to the study both in English and Tamil format.

Data collection: The following data were collected.

- Demographic details like name, age, gender, OPD no. and educational status

- Prescription details like number of drugs, name of the individual drugs, dosages, dosing schedule and duration of drugs.

- On the follow up, history of adverse events if any were noted.

Data analysis: The data analysis were done as follows:

a) Assessment of prescription pattern as per WHO/INRUD drug use indicators b) Classification of prescribed drugs according to the anatomical therapeutic chemical (ATC)- defined daily dose (DDD)

c) The prescribed daily dose (PDD) and its ratio to DDD was calculated.

\section{Results}

\section{Morbidity distribution pattern}

Out of the 80 prescriptions containing antidepressant drugs analysed, 55 prescriptions were of the diagnosis Depressive disorder, 7 were of Adjustment disorder, 6 were of Other anxiety disorders, 5 were of Schizoaffective disorder, 4 were of Obsessive compulsive disorder and 3 belongs to Alcohol dependence.

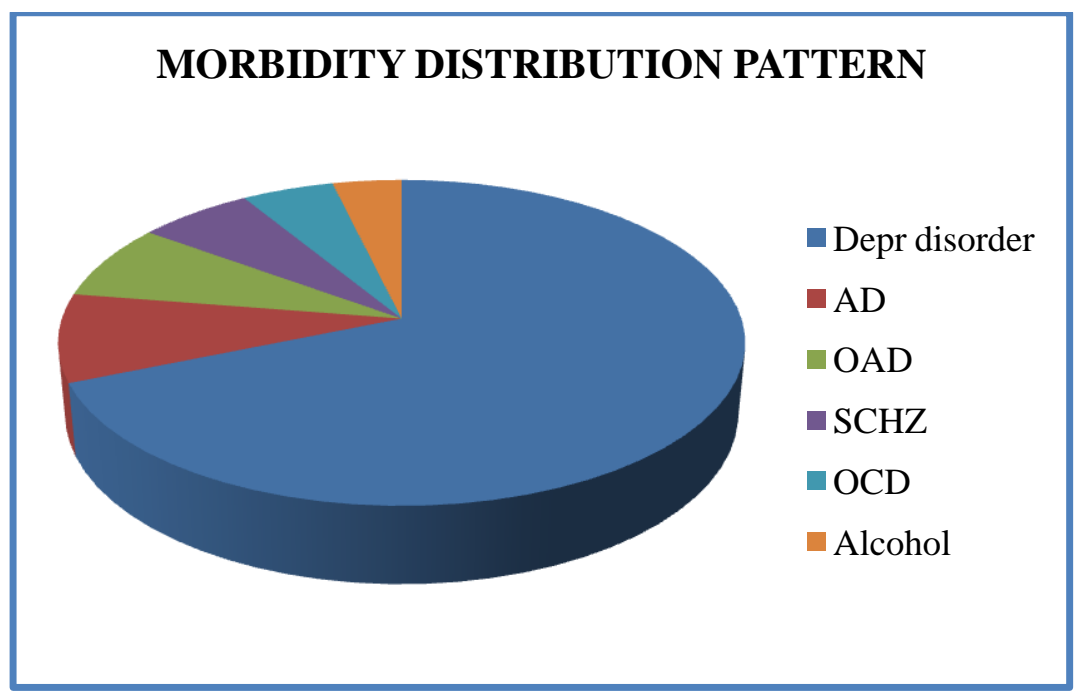

\section{Gender Distribution of Patients}

\begin{tabular}{|l|c|c|c|}
\hline \multirow{2}{*}{ Diagnosis } & \multicolumn{2}{|c|}{ Sex } & \multirow{2}{*}{ Total } \\
\cline { 2 - 3 } & Male & Female & \\
\hline Depressive disorder & 21 & 34 & 55 \\
\hline Adjustment disorder & 4 & 3 & 7 \\
\hline Obsessive disorder & 3 & 3 & 6 \\
\hline Schizoaffective disorder & 4 & 1 & 5 \\
\hline Obsessive compulsive disorder & 3 & 1 & 4 \\
\hline Alcohol dependence & 3 & - & 3 \\
\hline & $37(46.25 \%)$ & $43(53.75 \%)$ & 80 \\
\hline
\end{tabular}

Among the study participants, the percentage of males were $46.25 \%$ and females were $53.75 \%$. The relative distribution of patients prescribed with antidepressant medications, with respect to their to their age and sex are shown in table 2 and 3 . The age range was $12-68$ years. 


\begin{tabular}{|l|c|c|c|c|c|}
\hline \multirow{2}{*}{ Diagnosis } & \multicolumn{4}{|c|}{ Age groups ( years ) } & \multirow{2}{*}{ Total } \\
\cline { 2 - 5 } & $<\mathbf{2 0}$ & $\mathbf{2 0 - 4 0}$ & $\mathbf{4 1 - 6 0}$ & $>\mathbf{6 0}$ & \\
\hline Depressive disorder & 3 & 30 & 21 & 1 & 55 \\
\hline Adjustment disorder & 2 & 3 & 1 & 1 & 7 \\
\hline Other anxiety disorder & - & 2 & 3 & 1 & 6 \\
\hline Schizoaffective disorder & - & 4 & 1 & - & 5 \\
\hline Obsessive compulsive disorder & - & - & 3 & 1 & 4 \\
\hline Alcohol dependence & - & 2 & 1 & - & 3 \\
\hline TOTAL & 5 & 41 & 30 & 4 & 80 \\
& $(6.25 \%)$ & $(51.25 \%)$ & $(37.50 \%)$ & $(5 \%)$ & \\
\hline
\end{tabular}

\section{Assessment of Prescription Pattern as per WHO/INRUD Drug use Indicators}

\begin{tabular}{|l|l|c|}
\hline S.No & Drug use indicators & Result \\
\hline 1 & Average number of drugs per prescription & 2.7 \\
\hline 2 & Average number of antidepressants per prescription & 1.01 \\
\hline 3 & Percentage of drugs prescribed by generic names & $72.57 \%$ \\
\hline 4 & Percentage of prescriptions containing FDCs & 14.81 \\
\hline 5 & Percentage of antidepressants prescribed from the Tamilnadu essential drug list & $60 \%$ \\
\hline 6 & Percentage of antidepressants dispensed from hospital drug store at free of cost & $60 \%$ \\
\hline 7 & Percentage of antidepressants purchased by patients at cost & $40 \%$ \\
\hline
\end{tabular}

A total of 216 drugs were contained in 80 prescriptions. Out of the 216 drugs, 81 were antidepressants. Various other features observed are,

1. The average number of antidepressants per prescriptions were 1.01 .

2. A large proportion of drugs were prescribed with generic names and these drugs are available at free of cost.
3. The drugs which were prescribed for cost are prescribed with proprietary names.

4. The only FDC which was used in the prescriptions was Escitalopram and Clonazepam in different dose combinations.

ATC/DDD Classification of Drugs Used in Depressive Disorder

\begin{tabular}{|l|c|c|c|c|}
\hline DRUG & ATC & PDD & DDD & PDD/DDD \\
\hline Escitalopram & N06AB10 & 9.73 & 10 & 0.973 \\
\hline Clonazepam & N03AE01 & 0.509 & 8 & 0.06 \\
\hline Mirtazapine & N06AX11 & 7.5 & 30 & 0.25 \\
\hline Quitiapine & N05AH04 & 30 & 40 & 0.75 \\
\hline Amitryptiline & N06AA09 & 29.16 & 75 & 0.388 \\
\hline Diazepam & N05BA01 & 5 & 10 & 0.5 \\
\hline Lorazepam & N05BA06 & 1.83 & 2.5 & 0.732 \\
\hline Olanzapine & N05AH03 & 9 & 10 & 0.9 \\
\hline Sodium valproate & N03AG01 & 491.66 & 1500 & 0.327 \\
\hline Propranolol & C07AA05 & 30 & 160 & 0.187 \\
\hline Lithium & N05AN01 & $13 m m o l$ & $24 m m o l$ & 0.541 \\
\hline Nitrazepam & N05CD02 & 5 & 5 & 1 \\
\hline Sertralin & N06AB06 & 57.14 & 50 & 1.142 \\
\hline Alprazolam & N05BA12 & 0.25 & 1 & 0.25 \\
\hline Risperidone & N05AX08 & 2 & 5 & 0.4 \\
\hline Fluoxetine & N06AB03 & 12.72 & 20 & 0.636 \\
\hline
\end{tabular}

1. The PDD/DDD ratio for sertralin was highest ranging to 1.142 while for nitrazepam and escitalopram, it was almost equal to 1 .
2. For other antidepressant drugs used, the ratio was less than one ranging from 0.25 for mirtazapine to 0.636 for fluoxetine.

3. The PDD/DDD ratio for other drugs used with antidepressants are less than one 
ranging from 0.06 for clonazepam to

0.732 for lorazepam.

\section{Drugs Co-Prescribed With Antidepressants}

\begin{tabular}{|l|c|c|}
\hline Co-prescribed & Drugs & \\
\hline Class of drug & Percentage of prescription \\
\hline Vitamin supplements & B complex tablet & $37.5 \%$ \\
\hline Anti-anxiety (benzodiazepines) & Clonazepam & $68.75 \%$ \\
\cline { 2 - 3 } & Lorazepam & $15 \%$ \\
\cline { 2 - 3 } & Diazepam & $1.25 \%$ \\
\cline { 2 - 3 } & Alprazolam & $7.5 \%$ \\
\hline Mood stabilizers & Divalproate sodium & $13.75 \%$ \\
\hline H2 receptor blockers & Ranitindine & $11.25 \%$ \\
\hline Antipsychotics & Quetiapine & $11.25 \%$ \\
& Olanzapine & \\
& Risperidone & \\
\hline
\end{tabular}

The other drugs co-prescribed with antidepressants were antipsychotics, benzodiazepines, vitamin B complex, Multivitamin, H2 blocker etc. Among the antipsychotics- quetiapine, olanzapine and risperidone were the drugs found in $11.25 \%$ of prescriptions. Among the antianxiety drugs diazepam, lorazepam, clonazepam and alprazolam were the commonly prescribed drugs found in $1.25 \%, 15 \%, 68.75 \%$ and $7.5 \%$ of prescriptions respectively. Among the anti ulcer drugs, Ranitidine-H2 blocker was the commonly prescribed drug found in $11.25 \%$ of prescriptions. The tablet B-complex was found in $37.5 \%$ of prescriptions. Divalproate sodium is the mood stabilizer prescribed in $13.75 \%$ of prescriptions.

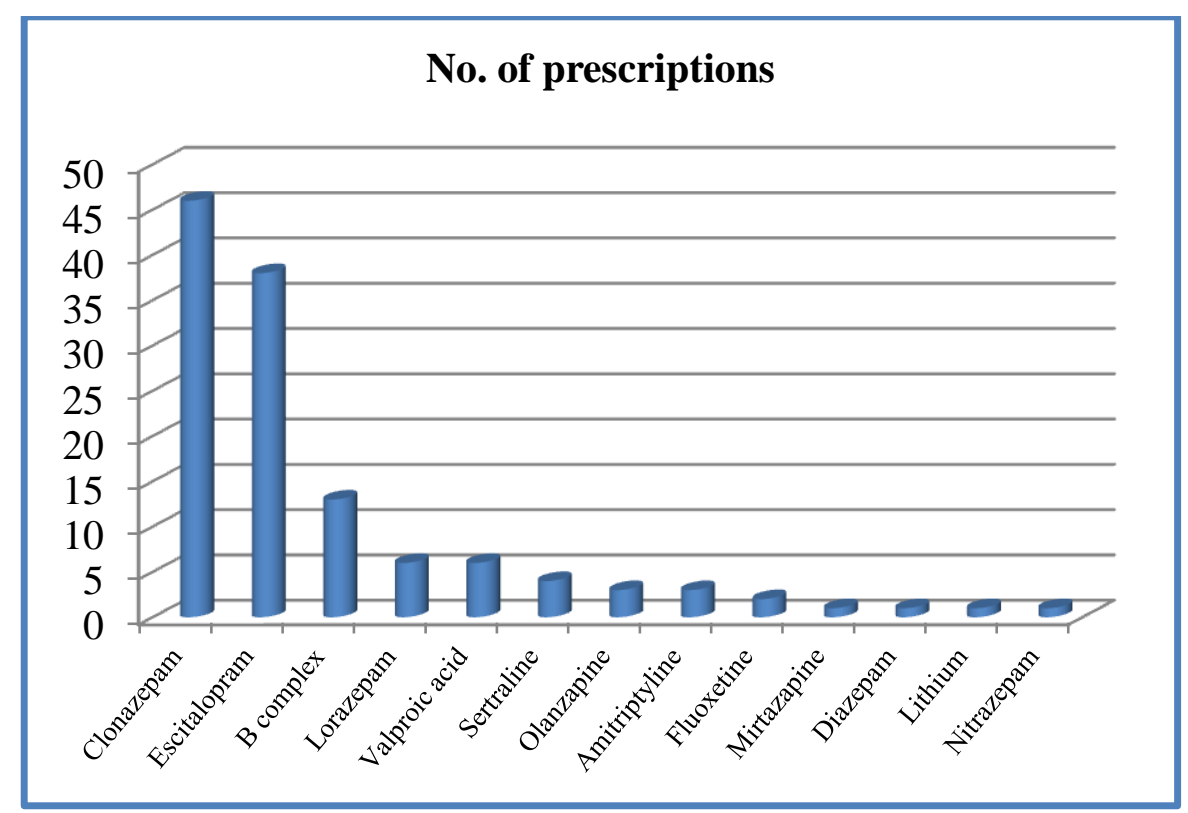

Observed prescription pattern in depressive disorder

Clonazepam is a benzodiazepine commonly prescribed along with antidepressant medications in about $86.63 \%$ of prescriptions. The most commonly prescribed antidepressant in depressive disorder was escitalopram and the least commonly prescribed was mirtazapine. Mood stabilizer such as valproate was also prescribed for few cases. 


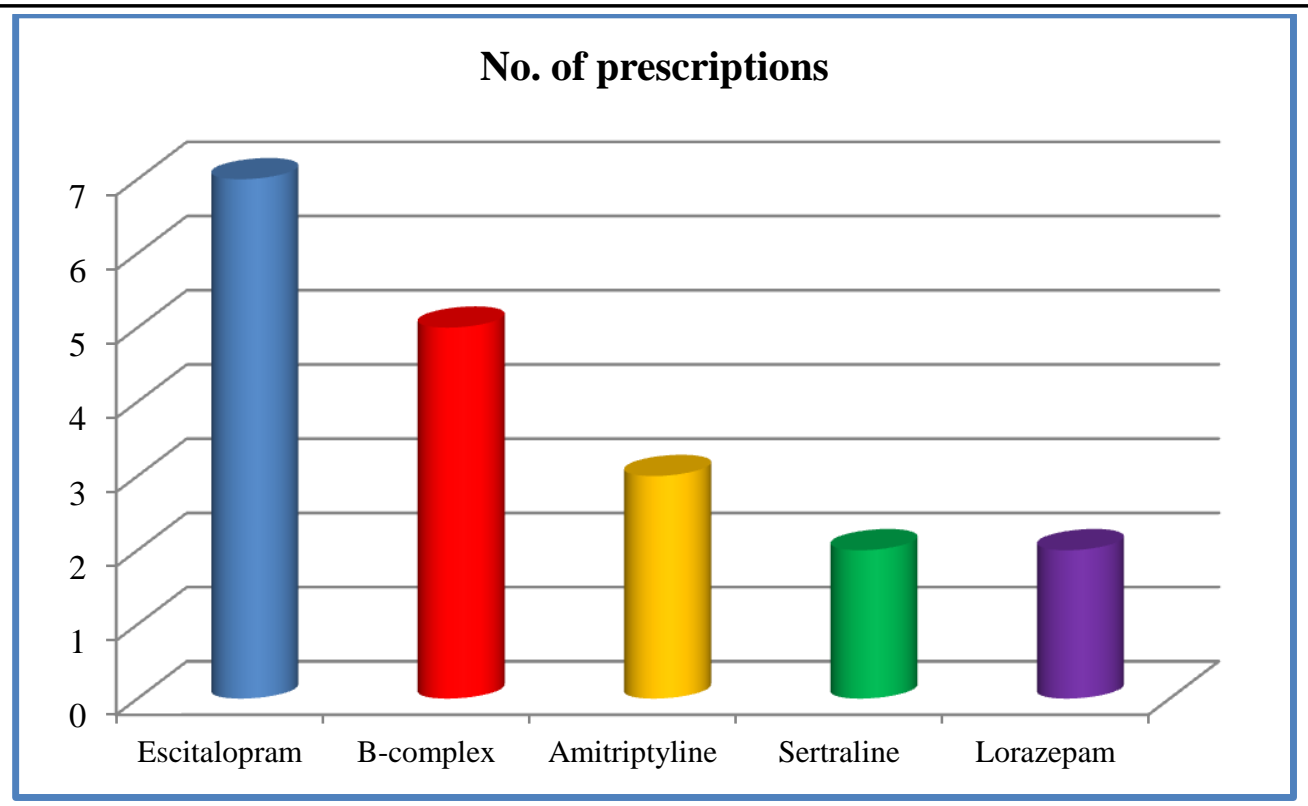

Observed prescription pattern in Adjustment disorder

Escitalopram was the most common antidepressant prescribed for patients diagnosed with adjustment disorder followed by amitriptyline and sertraline. Among the benzodiazepines, lorazepam was prescribed.

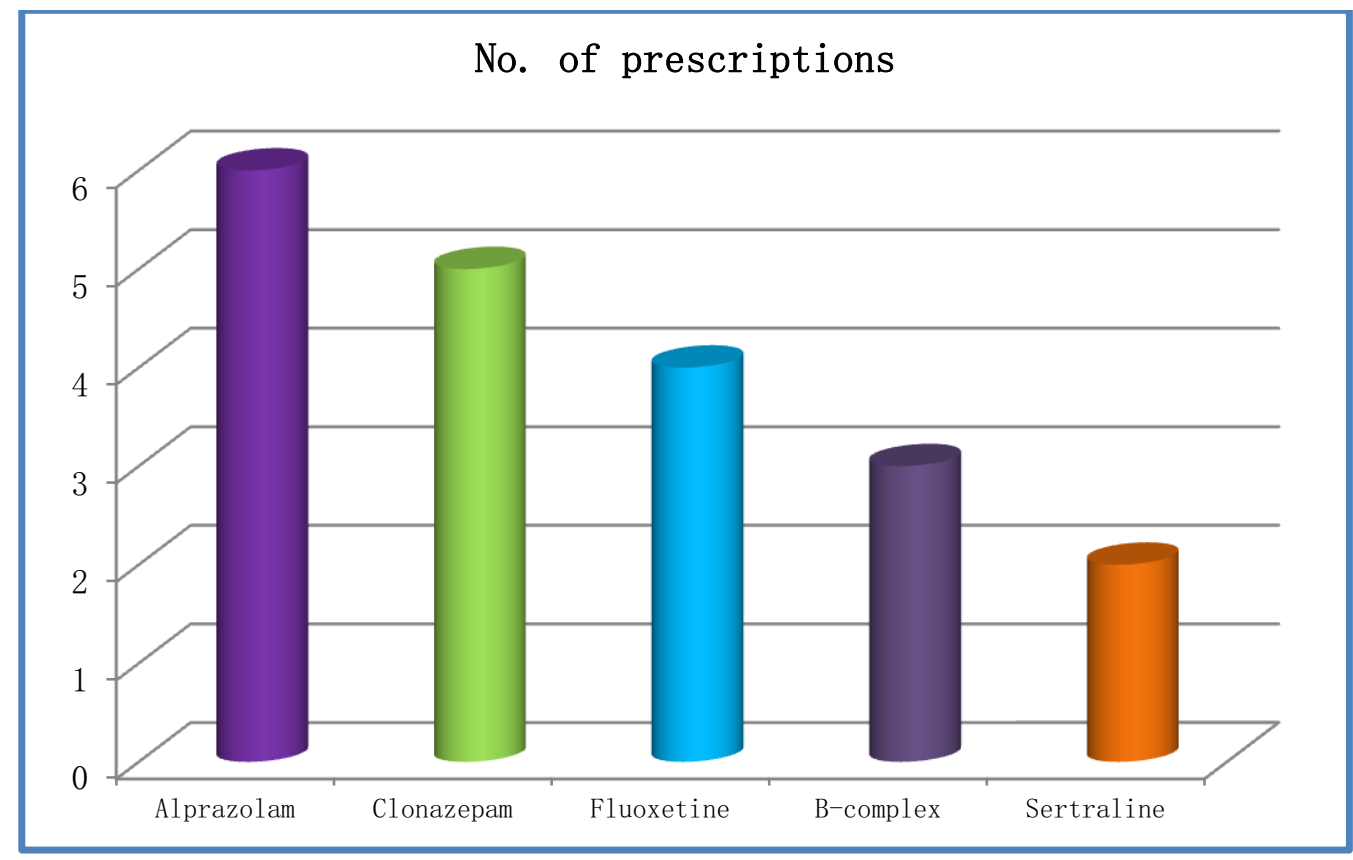

\section{Observed prescription pattern in other anxiety}

\section{disorder}

In case of anxiety disorders, benzodiazepines are used in which alprazolam aws more frequently prescribed drug followed by clonazepam. The other drugs which were prescribed were selective serotonin reuptake inhibitors in which fluoxetine is most prescribed and sertraline least. 


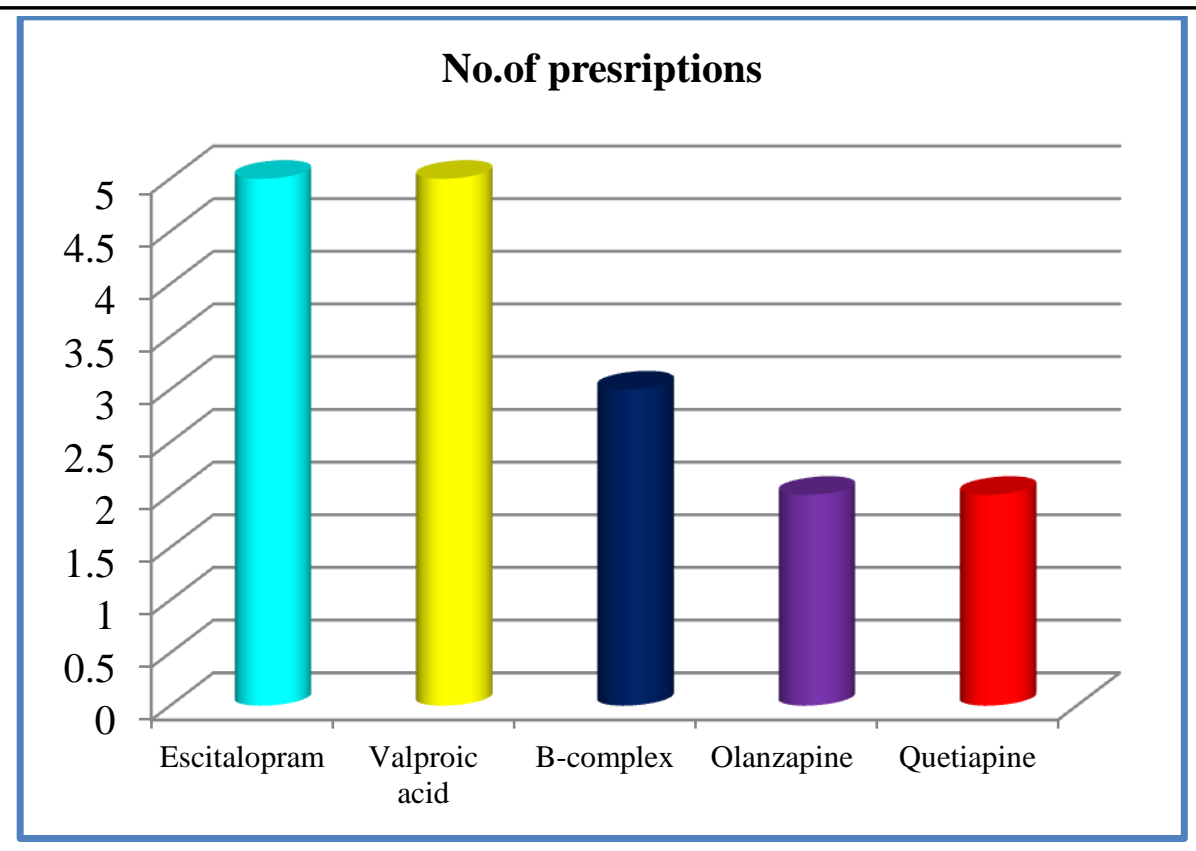

Observed prescription pattern in Schizoaffective disorder

In case of schizoaffective disorder, the most common class of drug prescribed were selective serotonin reuptake inhibitors such as escitalopram.
Other drugs prescribed along with antidepressants were mood stabilizers such as valproic acid seen in 83.3\% of prescriptions. Additionaly antipsychotics such as quetiapine and olanzapine were also prescribed.

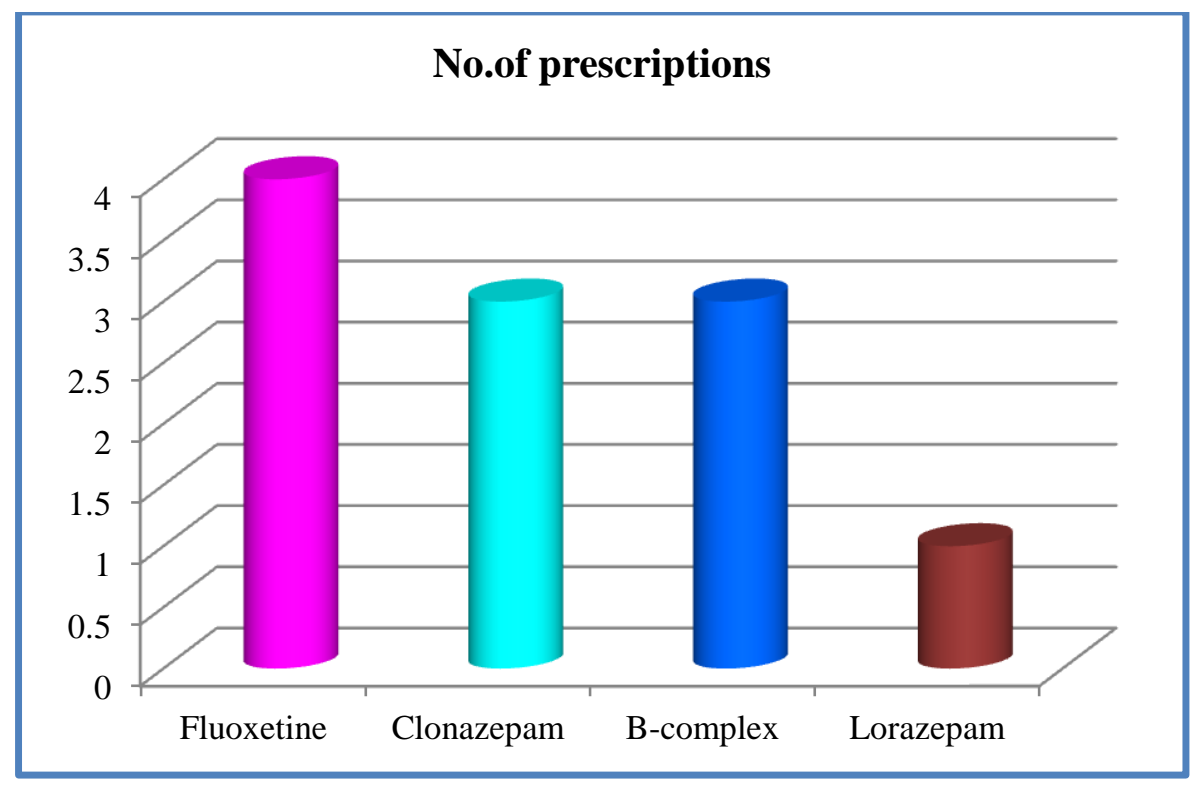

Observed prescription pattern in obsessive compulsive disorder

The most common group of drug prescribed for this case was selective serotonin reuptake inhibitors such as fluoxetine. The other drugs prescribed along with antidepressants were benzodiazepines such as clonazepam seen in $75 \%$ of prescritions followed by lorazepam. 


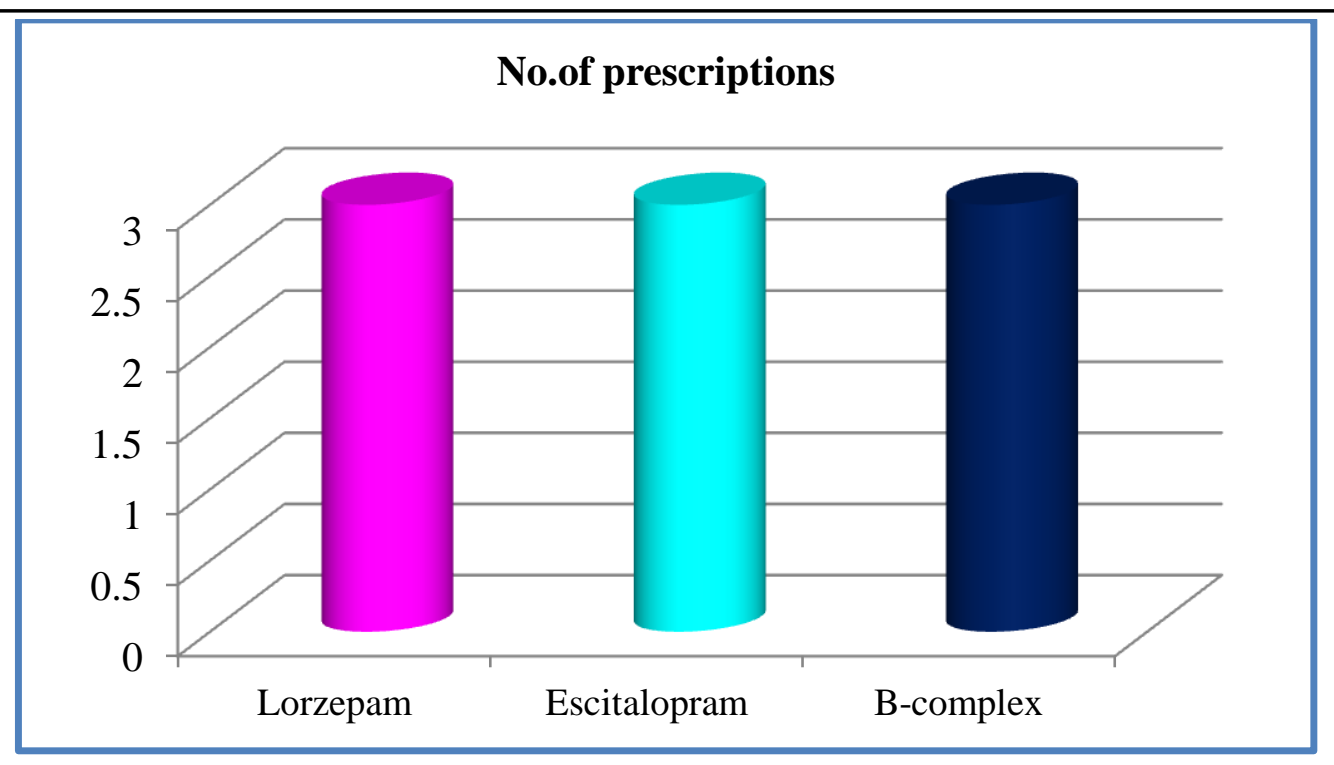

\section{Observed prescription pattern in alcohol} dependence

For this case, the most common class of drug used was benzodiazepines such as lorazepam. Among the antidepressant drugs that were prescribed, escitalopram was the most prescribed drug. All the patients with this diagnosis were prescribed multivitamin tablets also.

Adverse events encountered by the patients during follow up

\begin{tabular}{|l|c|c|c|}
\hline ADR reported & No of cases & Drug responsible & \% of patients \\
\hline \multirow{2}{*}{ Weight gain } & 10 & Escitalopram & $17.85 \%$ \\
\cline { 2 - 4 } & 1 & Fluoxetine & $9.09 \%$ \\
\hline \multirow{2}{*}{ Sedation } & 9 & Clonazepam & $16.66 \%$ \\
\hline \multirow{2}{*}{ Diarrhoea } & 5 & Lorazepam & $41.66 \%$ \\
\cline { 2 - 4 } & 2 & Fluoxetine & $18.18 \%$ \\
\hline Dryness of mouth & 1 & Sertralin & $14.28 \%$ \\
\hline Insomnia & 3 & Amitriptyline & $50 \%$ \\
\cline { 2 - 4 } & 1 & Escitalopram & $14.28 \%$ \\
\hline constipation & 1 & Sertraline & $14.28 \%$ \\
\hline
\end{tabular}

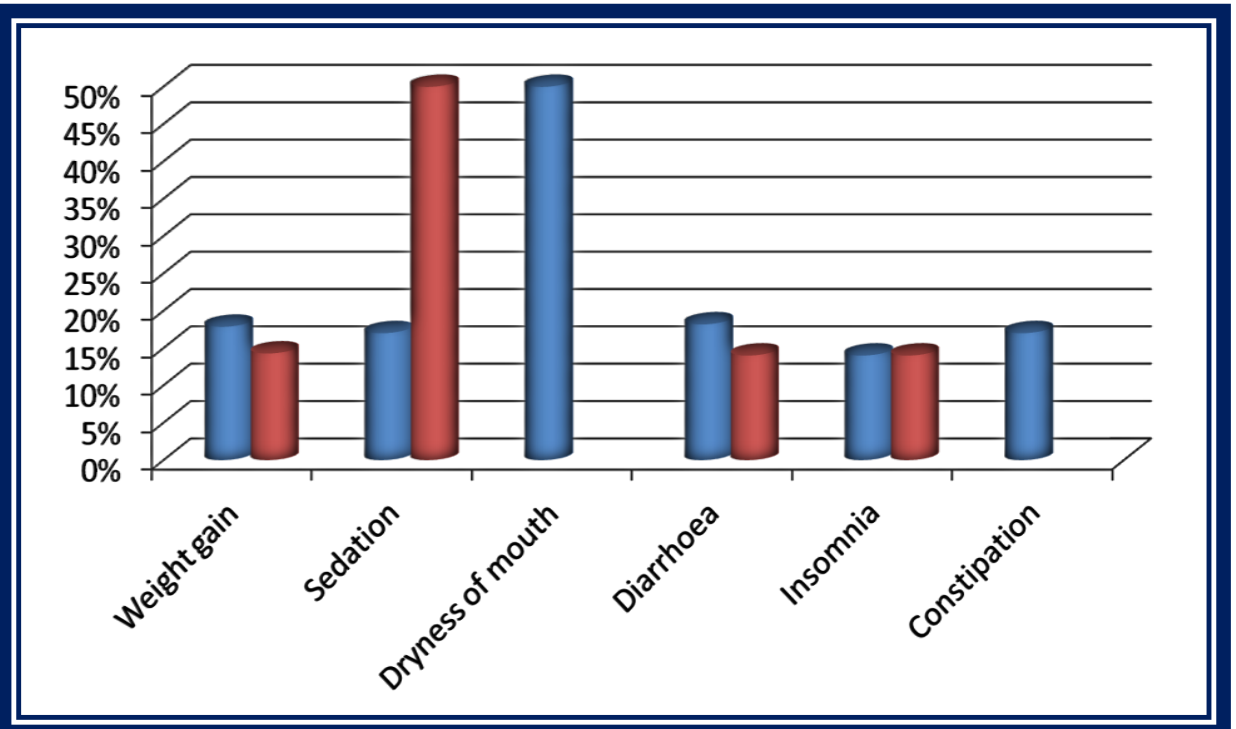

Adverse effects experienced by proportion of patients among exposed 


\section{Discussion}

\section{Morbidity distribution pattern}

Depressive disorder was the most common psychiatric diagnosis among the patients taking antidepressants accounting for $68.75 \%$ of prescriptions followed by Adjustment disorder accounting for $7.5 \%$, a finding similar to many studies. ${ }^{1,2}$

\section{Profile of study participants}

Among the patients taking antidepressants, females accounted for $57.69 \%$ and males $42.31 \%$. In a study conducted by Linda simoni et al, females outnumbered males ${ }^{6}$ and similar findings were noted in other studies also. ${ }^{7,8}$ Patients on antidepressants were mostly in the age group of $20-60$ years accounting to $88.75 \%$ of the total patients in which 20-40 years and 41-60 years contributed to $51.25 \%$ and $37.50 \%$ respectively. In a study conducted by Trivedi et al, patients on antidepressants in the age group of 20-60 were $93 \%$ which correlates well with our study. ${ }^{9}$ The prevalence of depressive disorders was more in females than in males, similar to a finding seen in a study. ${ }^{10}$ In a study conducted by Kuehner et al, women were diagnosed with depression more than men. ${ }^{11}$ Gender distribution has shown that the occurrence of depression is more in females similar to results of a study done in northern india. ${ }^{12}$ Literature also mentions that females suffer from depression more than males. ${ }^{13}$ The prevalence pattern of adjustment disorder showed $57.14 \%$ patients were females and $42.85 \%$ of them were males. A finding that correlates with a study conducted by Yaseen YA et al. ${ }^{14}$

\section{Prescription pattern analysis as per WHO/ INRUD}

The average number of drugs per prescription was 2.7 , a finding similar to many studies. ${ }^{15,1}$ In the analysis of prescription of antidepressants, it is found that a large proportion around $69.51 \%$ of drugs are prescribed in their generic names. It is well understood that generic drugs reduce the cost of therapy and is thus recommended. Generic substitution can be beneficial, provided, adequate quality control is assured. ${ }^{16}$ Among the prescribed drugs only $60 \%$ are from the state's essential list of medicines and are available free of cost. By including more drugs to the essential list of medicines, they can be made available free of cost to the patients which will decrease the economic burden of the disease and will improve the compliance of treatment removing the financial constraints.

The drugs which were prescribed with proprietary names are to be bought by patient at its own cost. Thus the socio economic status of a patient largely influences the selection of drugs for his diagnosis and here the role of pharmacoeconomics becomes significant which is explained clearly by Ajay Bera et al. ${ }^{17}$

\section{ATC/DDD classification}

When the PDD/DDD ratio is less than one it represents under utilisation and more than one represents over utilisation of drugs.

\section{Observed drug use pattern in depressive disorder}

The most frequent class of drug dispensed was SSRI followed by TCA similar to other studies done in Italy and India. $^{21,20}$ Reason behind frequent use of SSRIs compare to TCAs is lesser side effects and better tolerability than the latter. ${ }^{19}$ Escitalopram was the most common antidepressant prescribed overall and among SSRI also. Amitriptyline was the most common drug among TCAs. Sertraline was prescribed to a least number of patients. In a multicenter study done by Grover at al, ${ }^{18}$ escitalopram was the most commonly prescribed anti depressant followed by sertraline.

Escitalopram and clonazepam was the most common combination used as polytherapy. Benzodiazepines are co-prescribed in about $69.09 \%$ of the depressive disorder cases. Among the benzodiazepines, clonazepam was the most commonly prescribed drug followed by lorazepam, diazepam and alprazolam.

Benzodiazepines are quite safe medications. Though their use reduces the requirement of anticholinergics, there is no significant improvement in the general mental state. ${ }^{22}$ They can lead to falls, particularly in the elderly. With 
long term use the adverse effects encountered were addiction, memory loss, depression, tolerance, and dependence outweighs the benefits and increased moratlity. ${ }^{23}$ These drugs are prescribed for acute therpay, maximum of four weeks or their minimum effective doses given in intermittent doses. $^{24}$

Observed drug use pattern in adjustment disorder

Antidepressants were prescribed in patients with adjustment disorder with brief depressive reaction or acute stress reaction. An analysis of pattern prescription of antidepressants showed significant increase in the prescription more among patients with less severe psychiatric disorders (among them, AD). This suggested that in general, AD based on symptoms is viewed as a depression, with no attention given to the concept of timelimited and stress related event that truly defines it. ${ }^{25}$ Among the antidepressant, there was a threefold increase in the use of SSRIs.

The second line treatment was benzodiazepines to tackle the depression component of adjustment disorder as antidepressants usually take two weeks to show clinical response. ${ }^{26}$

\section{Observed drug use pattern in other anxiety disorder}

Anxiolytics i.e. benzodiazepines remain the mainstay treatment followed by antidepressants. Among the anxiolytics, the most common drug used was alprazolam followed by clonazepam and lorazepam. In a study done at Manipal teaching hospital, Nepal similar finding was noted. ${ }^{27}$ indicating the use of shorter acting ones, as it is observed that continuous and prolonged use of longer acting Benzodiazepines results in dependence and withdrawal symptoms when the dosage is decreased or therapy is stopped. ${ }^{28}$ Antidepressants and Benzodiazepines are the most commonly prescribed psychotropic drugs. Published evidence just tells us that antidepressants are effective in moderate and severe depressive illness. ${ }^{29}$ Benzodiazepines are extremely effective in promoting sleep and relieving anxiety in short term. ${ }^{30}$
Observed drug use pattern in schizoaffective disorder

In a study conducted by Kingshuk lahon et al, the most common antidepressant which was prescribed for schizoaffective disorder was escitalopram, a finding similar to our study. ${ }^{1}$

Mood stabilisers are the most commonly prescribed group of drugs along with antipsychotics in which Divalproate sodium was frequently prescribed.

\section{Observed drug use pattern in Obsessive compulsive disorder}

Antidepressants were preferred in cases of obsessive compulsive disorder, particularly a SSRI- fluoxetine was started as first line treatment. SSRIs are the first-line of treatment as seen in many randomized controlled trials (RCTs), according to several metaanalyses, ${ }^{31}$.

\section{Observed drug use pattern In alcohol dependence}

For decreasing the withdrawaI symptoms, BZDs like Lorazepam was prescribed in our study which was in line with the studies done by Hoey LL et al, where Lorazepam was the common BZD being prescribed. ${ }^{33,32}$ Hence, BZDs are effective in treatment of withdrawal symptoms in alcohol dependent patients.

In our study multivitamins were prescribed to all patients with alcohol dependence.as seen in many studies. This indicates that multivitamins are necessary to treat nutritional deficiencies commonly suffered by alcoholic patients.

Alcohol dependence is associated with various psychiatric comorbidities. An integrated approach is essential to address this issue as seen in the study be Ismene, et al. ${ }^{34}$ In our study too other coexistent affective disorders were treated with antidepressants.

\section{Adverse events}

Weight gain during antidepressant treatment is either a symptom of depression or a residual symptom in patients who overeat when depressed. Weight gain is seen during both acute and chronic treatment with antidepressants and this mainly contributes to noncompliance. 
Antidepressants interfere with serotonin, the neurotransmitter that regulates anxiety, mood and controls appetite. These changes may increase cravings for carbohydrate-rich foods.

When people are depressed, their appetite is affected. So when antidepressants take effect, appetite usually increases.

Depression can also lead to fatigue and inactivity, and a lack of physical activity causes weight gain. If a person gains weight while taking antidepressants, it may indicate that the medication is not combating their depression effectively.

Escitalopram and fluoxetine showed an increase in in weight gain among patients which correlates exactly with study conducted by Fava et al. ${ }^{35}$

The other adverse effect which are commonly noted were sedation, dryness of mouth and constipation by amitriptyline which was also noted in many studies.

The most frequently co prescribed antidepressant was sertraline which produced diarrhoea and insomnia in few patients.

\section{Conclusion}

Among the patients receiving antidepressant medications, depressive disorder was the most common diagnosis followed by adjustment disorder, other anxiety disorder, schizoaffective disorder, obsessive compulsive disorder and alcohol dependence.

- A significant percentage of patients of cases falls in the age group of 20-40 years followed by 41-60 years.

- A larger proportion of drugs has been prescribed in their generic names.

- The average number of antidepressants per prescription was 1.01 .

- In depressive disorder, the most common drg prescribed single drug was escitalopram amd two drug therapy was escitalopram and clonazepam while the least commonly prwscribed drugs were nitrazepam and lithium.
- In adjustment disorder, the most commonly prescribed antidepressant drug was escitalopram and sertraline.

- The most commonly co prescribed antidepressant and anti anxiety drug were fluoxetine and alprazolam respectively.

- A minor part of the total cost per prescription was borne by the patients and this indicates majority of the drugs available at free of cost.

- The principles of rationality in prescribing the drugs were followed according to the various drug use indicators given by WHO/INRUD.

\section{Conflict of Interest: Declared None}

\section{References}

1. Kingshuk Lahon, Harsha M. Shetty, Amith Paramel, Gyaneswar Sharma. A Retrospective Drug Utilization Study of Antidepressants in the Psychiatric Unit of a Tertiary Care Hospital. Journal of Clinical and Diagnostic Research. 2011 October, Vol-5(5): 1069-1075

2. Vasundhara Yerkade, Riyaz Ahmed Siddiqui. A drug utilization study of antidepressant drugs in a tertiary care hospital. http://dx.doi/org/10.18203/2319 -2003.ijbcp2017

3. Dr. Shaktibala Dutta, Dr. Vijay Kaul, Dr. Mirza Atif Beg, Dr. Nand Kishore Singh, 5Dr. Srihari Dutta, Dr. Shalu Bawa, Dr. Mohammad Anjoom, Dr. Saubhagya Sindhu, Dr. Ankita Negi. A comparative drug utilization study of depression patients between tertiary care teaching hospital and private practitioners of dehradun city, uttarakhand. Journal of Drug Delivery \& Therapeutics. 2015; 5(2):45-49 4

4. Avasthi A, Grover S, Aggarwal M. Research on antidepressants in India. Indian J Psychiatry. Jan 2010; 52(1):S34154.

5. World Health Organization. Introduction to Drug Utilization Research; 2003. Available from: 
http://www.who.int/medicines/areas/qualit y_safety/safety_efficacy/Drug. [Last cited on 2013 Sep 10].

6. L. Simoni- Wastila. Gender and psychotropic drug use. Med Care. 1998 Jan; 36(1): 8894.

7. Morabia A, Fabre J, Dunand JP. The influence of patient and physician gender on the prescription of psychotropic drugs. J Clin Epidemiol 1992;45:111-6.

8. The ESEMeD/MHEDEA 2000 investigators. Psychotropic drug utilization in Europe: results from the European Study of the Epidemiology of Mental Disorders (ESEMeD) project. Acta Psychiatr Scand 2004;109 (Suppl. 420):5564.

9. J. K. Trivedi*, Mohan Dhyani, Himanshu Sareen, V. S. Yadav and S. B. Rai. Antidepressant drug prescription pattern for depression at a tertiary health care center of Northern India.

http://www.academicjournals.org/mpr

ISSN 2I41-2596 C 2010 Academic Journals

10. Albert PR. Why is depression more prevalent in women? Journal of Psychiatry \& Neuroscience: JPN. 2015;40(4):219221. doi:10.1503/jpn.150205.

11. Why is depression more common among women than among women.Christine kuehner. https://doi.org/10.1016/S22150366(16)30263-2

12. Mishra S, Swain T, Mohanty M. Patterns of prescription \& efficacy evaluation of antidepressants in a tertiary care teaching hospital in Eastern India. Asian J Pharm Clin Res 2012;5(3):193-6.

13. Reus VI. Mental disorders. In: Fauci AS, Kasper DL, Longo DL, Hauser SL, Jameson JL, Loscalzo J, editors. Harrison's Principles of Internal Medicine. 18th ed. New Delhi: McGraw-Hill; 2012. p. 3529-45.

14. Adjustment disorder: Prevalence, sociodemographic risk factors, and its subtypes in outpatient psychiatric clinic. Yaseen YA ${ }^{1}$. Asian J Psychiatr. 2017 Aug;28:82-85.

doi: 10.1016/j.ajp.2017.03.012. Epub 2017 Mar 16

15. Memom A, Patel K. drug use pattern of antidepressant agents in psychiatric patients-a prospective study. NHL Journal of Medical Sciences 2013; 2(2):33-6.

16. Mathew, P. (2015). Generic drugs: Review and experiences from South India.Journal of Family Medicine and Primary Care, 4(3), 319-323. http://doi.org/10.4103/2249-4863.161305 https://www.ncbi. nlm.nih.gov/pmc/articles/PMC4535086/

17. Ajay Bera,Ashish Mukherjee et al ; The Importance Of Generic Drugs In India; IJPCBS 2012, 2(4), 575-587 http://www.ijpcbs.com/ files/volume2-42012/22.pdf

18. Grover S, Avasthi A, Kalita, Dalal PK, Rao GP, Chadda RK, et al. IPS multicentric study - Antidepressant prescription patterns. Indian $\mathbf{J}$ Psychiatry 2013; 55:41-5.

19. O'Donnell JM, Shelton RC. Drug therapy of depression and anxiety. In: Brunton LL, Chabner BA, Knollmann LL, editors. Goodman \& Gilman's the Pharmacological Basis of Therapeutics. 12th ed. New Delhi: McGraw Hill; 2011. p. 397-415.

20. Sultana J, Italiano D, Spina E, Cricelli C, Lapi F, Pecchioli S, et al.Changes in the prescribing pattern of antidepressant drugs in elderly patients: An Italian, nationwide, population-based study. Eur J Clin Pharmacol 2014;70(4):469-78.

21. Ghosh S, Roychaudhury S. Prescribing pattern of antidepressant drugs in a tertiary care hospital of eastern India. J Chem Pharm Res 2014;6(6):2593-7.

22. HHVolz A, Khorsand V, Gillies D, Leucht S: Benzodiazepines for schizophrenia: Cochrane Database Syst Rev. 2007 Jan 
24;(1):CD006391.

https://www.ncbi.nlm.nih.gov/pubmed/172 53592

23. Kripke DF, Langer RD, Kline LE. Hypnotics' association with mortality or cancer: a matched cohort study. BMJ open. [Internet]. 2012 Jan. Available from: http://www.ncbi.nlm.nih.gov/pmc/articles/ PMC3293137/.

24. Ashton H. Guidelines for the rational use of benzodiazepines. When and what to use. Drugs. [Internet]. 1994 Jul;48(1):25-40. Available

from: http://www.ncbi.nlm.nih.gov/pubmed/7525 193.

25. Olfson M, Marcus SC, Pincus HA, Zito JM, Thompson JW, Zarin DA: Antidepressant prescribing practices of outpatient psychiatrists. Arch Gen Psychiatry 1998, 55:310-6.

26. Nguyen N, Fakra E, Pradel V, Jouve E, Alquier C, Le Guern ME, Micallef J, Blin O: Efficacy of etifoxine compared to lorazepam monotherapy in the treatment of patients with adjustment disorders with anxiety: a double-blind controlled study in general practice. Hum Psychopharmacol 2006, 21:139-49.

27. Banerjee I 1, Roy B2, Sathian B3, Banerjee I 4, Kumar SS5, Saha A. Medications for Anxiety: A Drug utilization study in Psychiatry Inpatients from a Tertiary Care Centre of Western Nepal Article in Nepal Journal of Epidemiology January 2011;1(4): 119$125\{8\}$

28. Tyrer PJ. Benzodiazepine dependence and propranolol. Pharmaceutical Journal 1980; 225 : 158-60. $\{9\}$

29. Morris JB, Beck AT. The efficacy of antidepressant drugs. A review of research
(1958-1972).Arch Gen Psychiatry 197; 30(5):667-74. $\{10\}$

30. Lader MH, Bond AJ, James DC. Clinical comparison of anxiolytic drug therapy. Psychol Med 1974; 4(4):381-7.\{11

31. Stein DJ, Ipser JC, Baldwin DS, Bandelow B. Treatment of obsessive-compulsive disorder. . . CNS Spectr. 2007;12(suppl 3):28-35.

32. DUBE, Upasana et al. Prescribing pattern of drugs in alcohol dependence in a tertiary care hospital. International Journal of Basic \& Clinical Pharmacology, [S.1.], v. 6 , n. 11 , p. 2621-2624, oct. 2017. ISSN 2279-0780

33. Hoey LL, Nahum A et al. A prospective evaluation of Benzodiazepine guidelines in management of patients hospitalized for alcohol withdrawal. PMID. 1994:579- 585.

34. Ismene LP, Gerardo G, Robert R. Comorbidity of Alcoholism and Psychiatric Disorders. NIAAA

35. How can antidepressants affect weight gain? Last reviewed Mon 25 September 2017 By Jayne Leonard Reviewed by Alan Carter, Pharm D. 